\title{
Temporal integration of partially displayed information into a whole reasonable picture for children
}

\author{
NAOYUKI OSAKA \\ Otemon-Gakuin University, Ibaraki, Osaka 567, Japan
}

\begin{abstract}
Children 3, 4, and 5 years old were asked to observe a line-drawing figure of a dog as it was moved behind a stationary vertical slit. An optimal velocity required for perceptual integration was measured as a function of age and slit width. The results suggest that younger children have poorer ability to integrate a short-term storage of accumulated visual data into a whole reasonable figure.
\end{abstract}

A brief visual display presented at one moment is retained in iconic storage so that it can be integrated with a display presented at a slightly later moment (McCloskey \& Watkins, 1978). Parks (1965) found an interesting visual effect, which appears to be closely related to postretinal integrative and storage processes. Adult subjects were asked to observe a line-drawing figure of a camel as it was moved back and forth behind a stationary vertical slit. Subjects reported seeing the camel as a whole when the figure passed behind the slit at $8-16 \mathrm{~cm} / \mathrm{sec}$. The velocities that Parks found to be optimal were on the order of $.25-.5 \mathrm{sec}$ for the $4-\mathrm{cm}$ passage of the figure behind the $.1-\mathrm{cm}$ slit. It is likely that this temporal integration may occur at the iconic storage level, since iconic storage has approximately the same visual persistence of $.25-.5 \mathrm{sec}$ (Eriksen \& Collins, 1967; Sperling, 1960; Osaka, Note 1).

What happens when the speed of a figure is progressively lowered? A "lower velocity version" of Parks' (1965) paradigm was introduced here to measure children's ability to integrate a short-term storage of accumulated visual fragments into a whole reasonable figure.

\section{METHOD}

\section{Subjects}

A total of 72 subjects (three age groups) participated: 3-yearolds (median age $=3.6$ years, $\mathrm{N}=24$ ), 4-year-olds (median age $=4.4$ years, $\mathrm{N}=24$ ), and 5-year-olds (median age $=5.5$ years, $\mathbf{N}=24$ ). Eight subjects from each age group participated in each slit condition.

\section{Apparatus}

A line-drawing figure of a dog was displayed on a CRT (P31 phosphor) driven by a Commodore PET-2001 microcomputer (Figure 1, Panel A). The speed of the figure was decreased from .6 to $.2 \mathrm{~cm} / \mathrm{sec}$ in steps of $.05 \mathrm{~cm} / \mathrm{sec}$ with descending series. The slit was cut in a piece of black paper

This work was supported in part by Grant 371038 from the Japan Ministry of Education. and was attached to the CRT surface. Slit widths used were $.5,1$, and $2 \mathrm{~cm}$ : Their visual angles were $.7,1.4$, and $2.8 \mathrm{deg}$, respectively. The velocity of the figure was automatically controlled by the software timer of the computer.

\section{Procedure}

The subjects were told that their task was to watch the slit and to report what they saw. They were also told to report only when they perceived the entire figure "as a whole." The velocity was measured when they reported "dog." The luminance of the figure contour was kept $70 \mathrm{~cd} / \mathrm{m}^{2}$.

\section{RESULTS AND DISCUSSION}

Significant differences were found for age $[\mathrm{F}(2,63)=$ $93.50, \mathrm{p}<.01]$ and slit width $[\mathrm{F}(2,63)=73.12, \mathrm{p}<.01]$. Further, a significant interaction effect was found $[F(4,63)=8.16, p<.01]$. The results are shown in Figure 1 (Panel B). Figure 1 indicates that as age decreased,

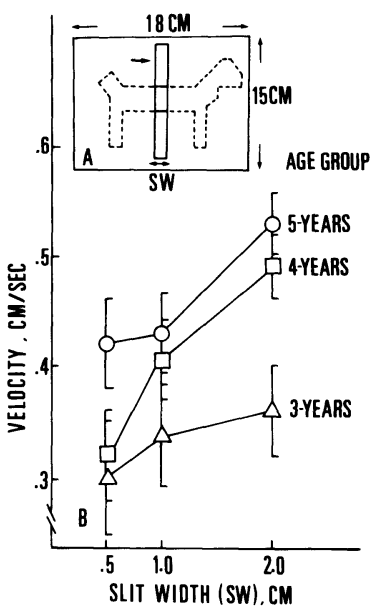

Figure 1. Panel A: Stimulus configuration on a CRT; “dog" as seen through the different sizes of slit width (SW). Panel B: Velocity required for correct response as a function of slit width. Parameter is age. Vertical bar indicates standard deviation. Each data point is a mean based on eight independent subjects. 
the optimal velocity decreased. Furthermore, as slit width increased, the velocity increased, although velocity appears to have been independent of slit width for the 3 -year-old children. The optimal velocity increased as a function of increasing slit width. This indicates that the velocity can be increased as the amount of available information increases. These results suggest that 3-yearold children have poorer ability to integrate a short-term storage of accumulated visual data into a whole reasonable figure (Osaka, 1980). This finding suggests that younger children are less able than older children to recognize figure patterns from such partial and successively displayed information. This can partly be explained in terms of poorer capacity of the short-term storage, as well as the lower processing speed for younger children. Thus, the phenomenon indicates that the perceptual integration (Hochberg \& Brooks, 1974) of a display presented over a relatively short temporal interval can occur at the level of short-term storage processing.

\section{REFERENCE NOTE}

1. Osaka, N. Minimum duration necessary for integration of briefly presented letters. Manuscript submitted for publication, 1981.

\section{REFERENCES}

Eriksen, C. W., \& Collins, J. F. Some temporal characteristics of visual pattern perception. Journal of Experimental Psychology, 1967, 74, 476-484.

Hochberg, J., \& Brooks, V. The integration of successive cinematic views of simple scenes. Bulletin of the Psychonomic Society, 1974, 4, 263.

McCloskey, M., \& Watkins, M. J. The seeing-more-than-isthere phenomenon: Implications for the locus of iconic storage. Journal of Experimental Psychology: Human Perception \& Performance, 1978, 4, 553-564.

OsAKA, N. Effect of peripheral visual field size upon visual search in children and adults. Perception, 1980, 9, $451-455$.

Parks, T. E. Post-retinal storage. American Journal of Psychology, 1965, 78, 145-147.

SPERLing, G. The information available in brief visual presentations. Psychological Monographs, 1960, 74(11, Whole No. 498). 